\title{
EMERGENCY BUTTON WIRELESS BERBASIS ARDUINO UNO
}

\author{
Kuat Indartono ${ }^{1}$, Teppei Jordy L'ga Tama ${ }^{2}$, Achmad Jauhar Mushthofa ${ }^{3}$ \\ ${ }^{1,2,3}$ Program Studi Teknik Informatika, STMIK Amikom Purwokerto \\ Purwokerto, Indonesia
}

\begin{tabular}{l} 
Informasi Makalah \\
\hline Dikirim, 17 September 2018 \\
Direvisi, 14 Januari 2019 \\
Diterima, 30 April 2019 \\
\end{tabular}

\section{Kata Kunci:}

Arduino

Emergency Button

Wireless

RF 315/443 MHz

\section{Keyword: \\ Arduino \\ Emergency Button \\ Wireless \\ RF 315/443 MHz}

\begin{abstract}
INTISARI
Dalam sebuah instansi, sering kali terjadi permasalahan saat jam kerja berlangsung yang kemudian membutuhkan bantuan bagian pelayanan dalam menyelesaikannnya. Maka dari itu, dibuatlah Emergency Button Wireless untuk mempermudah dalam proses pemanggilan. Dengan menggunakan modul RF 315/443 MHz Transmitter-Reciever, alat ini merupakan alat yang bersifat independent. Kelebihan penggunaan Arduino ini dapat digunakan untuk membedakan dari titik mana yang membutuhkan bantuan.
\end{abstract}

\begin{abstract}
In an institution, many problems often occur during working hours which then require the help of the service department to resolve them. Therefore, the Wireless Emergency Button is made to simplify the calling process. By using the 315/443 MHz Transmitter-Receiver RF module, this tool is an independent tool. The advantages of using Arduino can be used to distinguish from which points need help..
\end{abstract}

\section{Korespondensi Penulis:}

Kuat Indartono

Teknik Informatika

STMIK Amikom Purwokerto

Purwokerto, Indonesia

Email: indartono@amikompurwokerto.ac.id

\section{PENDAHULUAN}

Dalam proses kehidupan, manusia tidak dapat terhindar dari masalah. Masalah didefinisikan sebagai suatu pernyataan tentang keadaan yang belum sesuai dengan yang diharapkan. Bisa jadi kata yang digunakan untuk menggambarkan suatu keadaan yang bersumber dari hubungan antara dua faktor atau lebih yang menghasilkan situasi yang membingungkan [1]. Dalam penyelesaiannya, masalah dapat diselesaikan sendiri atau membutuhkan bantuan oranglain.

Pada sebuah instansi, terdapat bagian pelayanan yang bertugas untuk membantu menyelesaiakan masalah. Ketika kita memiliki masalah disuatu tempat, terkadang kita tidak bisa meninggalkan tempat tersebut untuk meminta bantuan. Selain itu, dalam kondisi darurat dibutuhkan bantuan yang cepat. Sebagai contoh kita ambil permasalahan yang timbut di rumah sakit. Sering kali ada pasien yang membutuhkan bantuan, yang kemudian pasien tersebut menekan tombol emergency yang akan menyalakan lampu yang terdapat didepan pintu ruang rawat. Ketika lampu menyala kemudian dating pertolongan. 
Namun, kekurangan dari alat ini, kita tidak bisa membedakan pasien mana yang membutuhkan bantuan jika diruangan tersebut terdapat lebih dari satu pasien. Oleh karena itu, muncul lah ide untuk membuat emergency button wireless dengan menggunakan Arduino Uno. Dengan menggunakan Arduino, kita dapat membedakan darimana titik yang membutuhkan bantuan. Selain itu alat ini bersifat independen dan tidak membutuhkan instalasi kabel dalam proses pemasangan.

\section{METODE PENELITIAN}

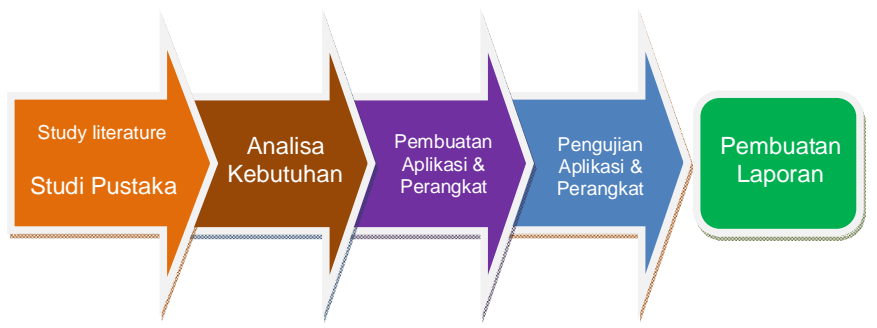

Gambar 1. Diagram Alur Tahapan Penelitian.

Berdasarkan Gambar 1, dalam penelitian ini akan dilakukan langkah-langkah sebagai berikut :

1. Study Literature

Study Literature mengenai penelitian-penelitaan yang ada.

2. Studi Pustakaan

Studi Pustakaan mengenai teori-teori pendukung yang berkaitan dengan penelitian.

3. Analisa Kebutuhan

Analisa Kebutuhan untuk mengetahui kebutuhan apa saja yang akan dipergunakan dalam aplikasi dan pembuatan perangkat dengan menggunakan data-data pada penelitian terdahulu.

4. Pembuatan Aplikasi dan Perangkat

Pembuatan apliksai pada Arduino uno menggunakan software Arduino. Peralatan yang digunakan antara lain receiver dan transmitter yang digunkan sebagai modul wireless pada penelitian kali ini. Input dari alat kali ini ialah button, yang selanjutnya akan diproses dengan menggunkan Arduino uno. Dan outputnya ditampilkan melalui display.

5. Pengujian Aplikasi dan Perangkat

Pada tahap pengujian baik aplikasi maupun perangkat dilakukan untuk mengetahui kinerja aplikasi dan perangkat yang telah dibuat bekerja dengan baik. Pengujian aplikasi langsung melakukan simulasi dengan meletakkan tombol pada ruang kelas dan perangkat Arduino dan display pada ruang laboran.

6. Pembuatan Laporan

Dari hasil-hasil pengujian diperoleh data-data sehingga dapat di pergunakan untuk menyusun laporan hasil penelitian.

Cara pengambilan data Emergency Button Wireless dengan menempatkan masing-masing alat transmitter pada ruang yang membutuhkan bantuan dan receiver pada ruang pelayanan. Pengiriman sinyal melalui modul RF 315/443 MHz Transmitter-Reciever. Modul RF 315/443 MHz Transmitter-Reciever dapat menjangkau jarak hingga 100 meter [9]. Parameter yang diuji adalah bagaimana menggabungkan beberapa input berupa push button yang ditujukan kedalam satu output, dimana sistem tersebut berbasis wireless. Spesifikasi sistem pada penelitian kali ini dapat dilihat seperti pada Tabel 1.

Tabel 1 Spesifikasi sistem

\begin{tabular}{clc}
\hline No. & \multicolumn{1}{c}{ Nama Perangkat } & Jumlah (Unit) \\
\hline 1 & Arduino Uno & 3 \\
2 & RF 315/433 MHz & 2 \\
& Transmitter Module & \\
3 & RF 315/433 MHz & 1 \\
4 & Receiver Module & 3 \\
5 & Button & 3 \\
6 & Resistor 330 Ohm & 6 \\
7 & Kabel & 30 \\
8 & Adaptor 5 volt & 2 \\
9 & Komputer Monitoring & 1 \\
\hline
\end{tabular}

Model skema sistem Emergency Wireless Button dapat dilihat pada Gambar 1. 


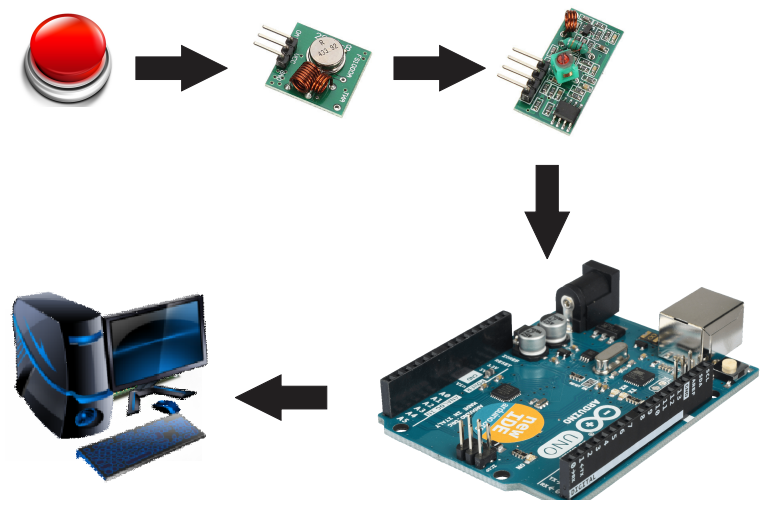

Gambar 2. Model skema sistem Emergency Wireless Button.

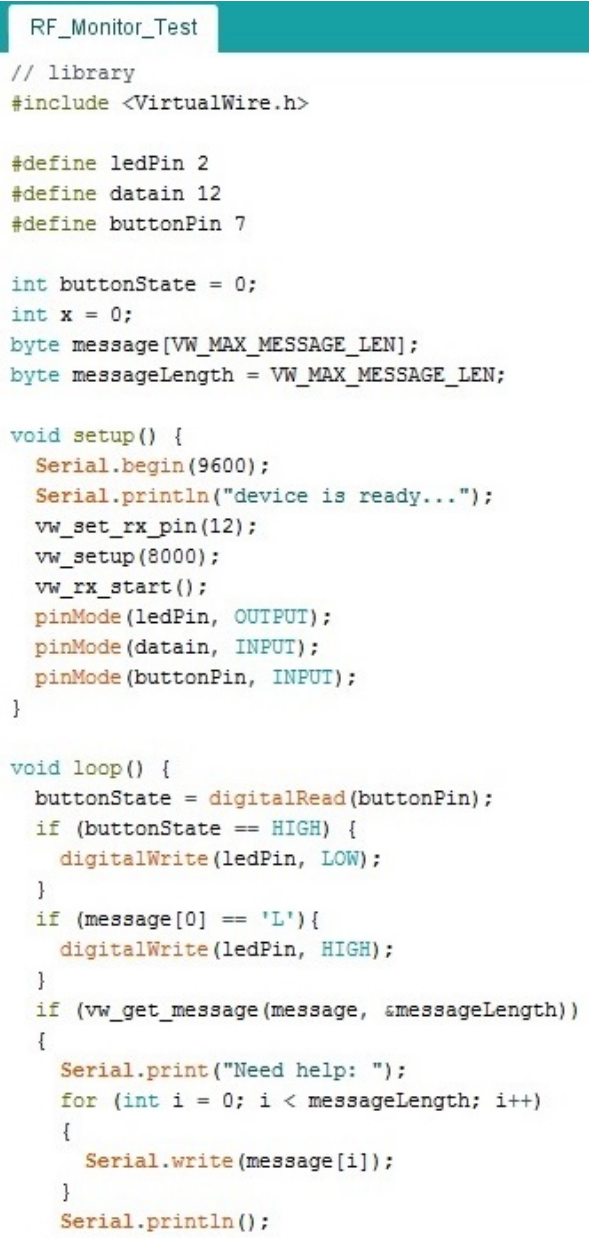

Gambar 3. Source Code Receiver Emergency Wireless Button.

Gambar 2 merupakan skema sistem Emergency Wireless Button. Prinsip kerjanya, ketika tombol ditekan, maka transmitter akan memancarkan sinyal. Sinyal tersebut kemudian akan ditangkap oleh receiver. Setelah itu, sinyal akan diubah menjadi digital dengan menggunakan perangkat Arduino yang kemudian akan ditampilkan pada layar komputer monitoring.

\section{HASIL DAN PEMBAHASAN}


Emergency Button Wireless ini tediri dari 3 buah alat, alat tersebut ialah 2 buah Transmitter dan 1 buah Receiver. Hal ini dimaksudkan untuk menunjukan jika Receiver dapat menerima lebih dari satu buah Transmitter. Karena pda prinsip kerja sebuah emergency button ialah memiliki beberapa titik dimana keluahan sering muncul dan memiliki satu tempat monitoring. Berikut ini adalah tahapan pembuatan alat Emergency Button Wireless.

\subsection{Pembuatan Source Code}

Source code adalah suatu rangkaian pernyataan atau deklarasi yang ditulis dalam bahasa pemrograman komputer yang terbaca manusia. Kode sumber yang menyusun suatu program biasanya disimpan dalam satu atau lebih berkas teks, dan dapat pula ditampilkan dalam bentuk cuplikan kode (code snippet) yang dicetak pada buku atau media lainnya [2].

Pembuatan source code dilakuakan dengan menggunakan software open source Arduino. Software Arduino menggunakan Bahasa pemrograman $\mathrm{C} / \mathrm{C}++$ yang sudah sangat familiar dan sering digunakan untuk pembuatan software aplikasi serta tidak diragukan lagi kehandalannya. Selain itu pada software Arduino telah dilengkapi berbagai driver untuk mengintegrasikan board Arduino dengan komputer [3][8]. Adapun salah satu hasil dari pembuatan source code seperti yang terlihat pada Gambar 3. Hasil dari pembuatan source code tersebut kemudian disimpan dalam format ino dan di export dalam format hex.

\subsection{Simulasi}

Simulasi alat Emergency Button Wireless menggunakan software Proteus 8.6. Software Proteus adalah sebuah software yang digunakan untuk mendesain PCB yang juga dilengkapi dengan simulasi PSpice pada level skematik sebelum rangkaian skematik di-upgrade ke PCB untuk memastikan PCB dapat berfungsi dengan semestinya. Proteus mengkombinasikan program ISIS untuk membuat skematik desain rangkaian dengan program ARES untuk membuat layout PCB dari skematik yang dibuat [4]. Sebelum menggunakan aplikasi proteus, dibutuhkan library tambahan [5] Skema rangkaian alat seperti yang ditunjukan pada Gambar 4.

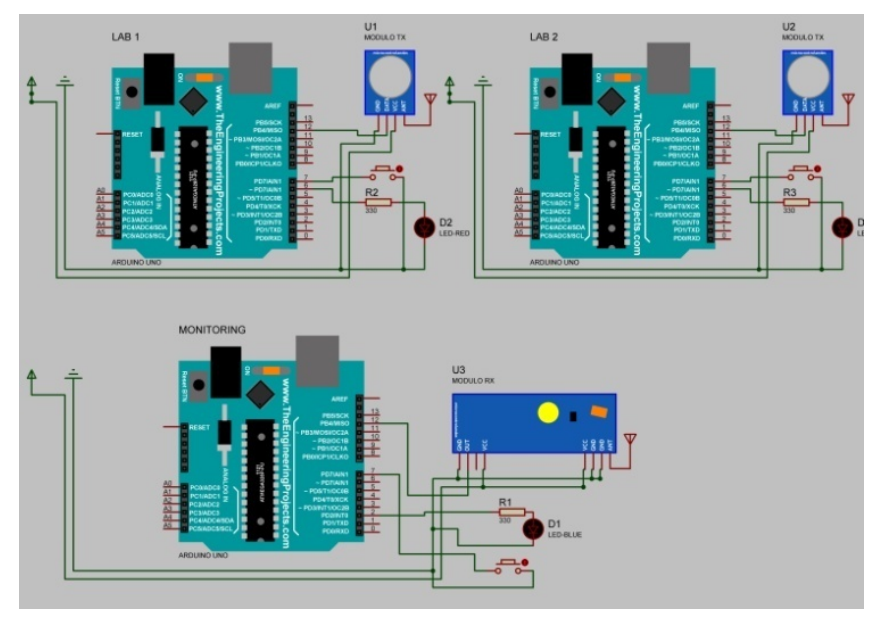

Gambar 4. Rangkaian Emergency Button Wireless.

\subsection{Pembuatan Perangkat}

Pembuatan perangkat Emergency Button Wireless ini menggunakan sebuah komputer dan modul Arduino Uno, RF 315/433 Transmitter-Receiver, Button, LED. Semua Komponen tersebut dirangkai menjadi satu kesatuan. Arduino Uno adalah papan mikrokontroler didasarkan pada ATmega328 (datasheet). Terdiri dari 14 pin digital input/output (6 pin dapat dimanfaatkan sebagai output PWM), 6 input analog, resonator $16 \mathrm{MHz}$ keramik, dilengkapi dengan konektivitas USB, jack listrik, header ICSP, dan tombol reset [6]. Board Arduino UNO dapat dilihat pada Gambar 5 [7]. Arduino banyak dipakai oleh peneliti pada berbagai bidang yang berkaitan dengan sistem kontrol yaitu itu smart system. 


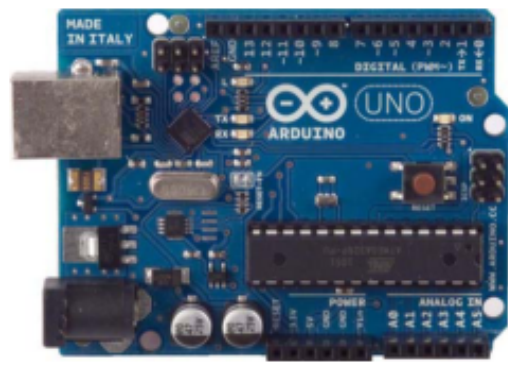

Gambar 5. Arduino Uno

Modul RF Transmitter terdapat 3 pin yang terdiri VCC, GND, Data. Pin VCC dihubungkan ke sumber tegangan 5 Volt Arduino Uno, pin GND dihubungkan pada Ground Arduino Uno, pin Data dihubungkan ke pin 12 Arduino Uno. Sedangkan modul RF Receiver terdapat 4 pin yang terdiri dari VCC GND, Data, Data. Pemasangan Receiver ini sama dengan Transmitter, hanya saja yang membedakan hanya salah satu pin Data saja yang digunakan. Button digunakan sebagai pengirim sinyal analog dihubungkan ke pin 7 Arduino Uno. LED berfungsi sebagai indicator bahwa alat bekerja dengan baik. Skema pada alat Emergency Button Wireless tersebut dapat dilihat seperti pada Gambar 6.

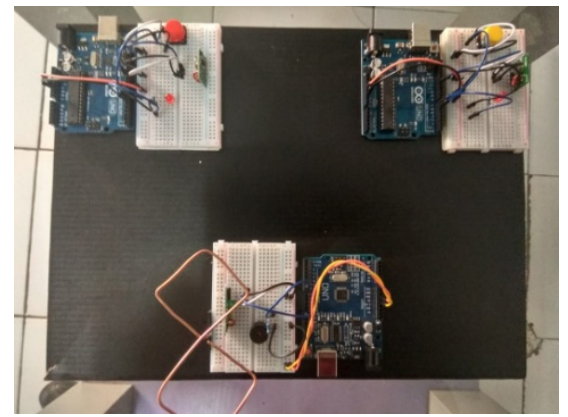

Gambar 6. Perangkat Emergency Wireless Button.

\subsection{Pengujian Perangkat}

Pengujian perangkat ini untuk mengetahui kerja alat dengan cara melakukan running test. Perangkat yang telah dirangkai sesuai dengan skema pada Gambar 6 ini diuji untuk mengetahui apakah perangkat tersebut bekerja sesuai denagn system yang diinginkan. Running test ini dinyatakan berhasil apabila pada serial monitor software Arduino menampilkan tulisan sesuai dengan darimana tombol tersebut ditekan. Pada pengujian kali ini dilakukan di Laboran STMIK Amikom Purwokerto. Alat Transmitter diletakkan pada masing-masing ruang laboratorium dengan menggunakan adapter $5 \mathrm{~V}$ sebagai sumber daya, sedangkan Receiver terhubung pada computer monitoring. Hasil dari pengujian alat seperti yang ditampilkan pada Gambar 7.

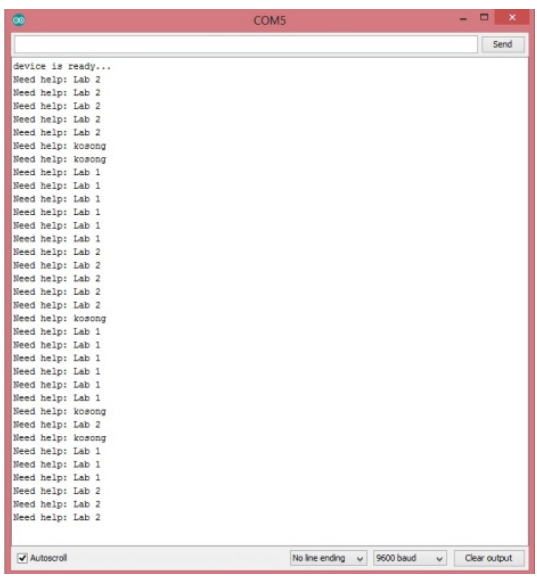

Gambar 7. Hasil serial monitor Emergency Wireless Button. 


\section{KESIMPULAN (10 PT)}

Arduino Uno dapat digunakan sebagai perangkat penyusun Emergency Button Wireless. Modul RF 315/443 MHz Transmitter-Reciever dapat digunakan sebagai pengirim sinyal multi-channel dengan jarak hingga lebih dari 60 meter.

\section{DAFTAR PUSTAKA}

[1] Vardiansyah, Dani. "Filsafat Ilmu Komunikasi: Suatu Pengantar", Indeks, Jakarta, 2008. Halaman 70

[2] Wikipedia. "Kode sumber". 12 Maret 2018. https://id.wikipedia.org/wiki/Kode_sumber.

[3] Rangkuti, Syahban. "Arduino \& Proteus: Simulasi dan Praktik", Informatika, Bandung, 2016. Halaman viii

[4] Immersa Lab. "SOFTWARE PROTEUS BESERTA FITUR-FITURNYA". 11 Maret 2018. lab.com/software-proteus-beserta-fitur-fiturnya.htm

[5] Rawashdeh, Mohannad. "RF 315/433 MHZ Transmitter-Receiver Module and Arduino”. 13 Maret 2018. http://www.instructables.com/id/RF-315433-MHz-Transmitter-receiver-Module-and-Ardu/.

[6] Kumar, N.S. et al., 2016. IOT Based Smart Garbage alert system using Arduino UNO. IEEE Region 10 Conference (TENCON), pp.1028-1034.

[7] Kumbhar, H., 2016. Wireless Sensor Network using Xbee on Arduino Platform An experimental study. International Conference on Computing Communication Control and automation (ICCUBEA), pp. 1 - 5

[8] Priyanka, S.S. et al., 2017. Android Controlled Fire Fighting Robot. IJSTE - International Journal of Science Technology \& Engineering, pp. 540-544

[9] Abdal-Khadim, A.M. et al, 2018. AN INVESTIGATION OF THE POWER CONSUMPTION OF 315 MHz RF ASK TRANSMITTER AND RECEIVER MODULES FOR WIRELESS SENSOR NETWORK NODE. IJSTE - International Journal 